\title{
Análise econômica sobre a inovação do sistema de iluminação pública no município
}

\section{de Rosana}

Economic analysis on innovation of public lighting system in Rosana city

Análisis económico sobre la innovación del sistema de alumbrado público en la ciudad de Rosana

Recebido: 22/12/2021 | Revisado: 28/12/2021 | Aceito: 29/12/2021 | Publicado: 30/12/2021

João Guilherme Resende Oliveira

ORCID: https://orcid.org/0000-0002-6624-7634 Universidade Estadual Paulista, Brasil E-mail: resende.oliveira@unesp.br

Leandro Ferreira Pinto

ORCID: https://orcid.org/0000-0002-0656-9471 Universidade Estadual Paulista, Brasil

E-mail: leandro.f.pinto@unesp.br

Kleber Rocha de Oliveira

ORCID: https://orcid.org/0000-0002-1260-6363 Universidade Estadual Paulista, Brasil

E-mail: kleber.oliveira@unesp.br

José Francisco Resende da Silva

ORCID: https://orcid.org/0000-0002-4671-0740 Universidade Estadual Paulista, Brasil E-mail: jose.resende@unesp.br

\begin{abstract}
Resumo
Esta pesquisa sugere a elaboração de um projeto de iluminação pública (IP) eficiente, levando em conta a viabilidade técnico-financeira das luminárias que compõem o sistema de IP do município de Rosana. É apresentado o estudo para levantar os potenciais de economia no consumo de energia elétrica e no valor pago mensalmente com IP. O trabalho tem como finalidade a substituição das luminárias convencionais (a vapor de sódio) que tem vida mediana curta e maior consumo energético, por luminárias led (Light Emitting Diode) que tem um tempo de vida útil média maior e são mais eficientes. A análise econômica foi feita com base em indicadores padrões de viabilidade de investimentos, como valor presente líquido (VPL), payback descontado e taxa interna de retorno (TIR). por fim, apresenta análises de dados com o intuito de otimizar o sistema de ip e reduzir o consumo de energia elétrica no município de Rosana.
\end{abstract}

Palavras-chave: Iluminação pública; Eficiência energética; Diodo emissor de luz.

\begin{abstract}
This research suggests the preparation of an efficient street lighting (IP) project, taking into account the technicalfinancial feasibility of the luminaires that make up the IP system in Rosana city. the study is presented to raise the saving potential in the consumption of electrical energy and in the amount paid monthly with ip. the work's purpose is to replace conventional luminaires (sodium steam), which has a short median life and greater energy consumption, by led luminaires (Light Emitting Diode) which have a longer average lifespan and are more efficient. The economic analysis was done based on standard indicators of investment feasibility, such as net present value (VPL), discounted payback and internal rate of return (TIR). Finally, presents data analysis with the purpose of optimizing the sl system and reducing electric energy consumption in the Rosana city.
\end{abstract}

Keywords: Street lighting; Energy efficiency; Light emitting diode.

\section{Resumen}

Esta investigación sugiere la elaboración de un proyecto de alumbrado público eficiente (IP), teniendo en cuenta la viabilidad técnica y financiera de las luminarias que integran el sistema IP en el municipio de Rosana. El estudio se presenta para relevar los ahorros potenciales en el consumo eléctrico y el monto que se paga mensualmente con IP. El objetivo del trabajo es sustituir las luminarias convencionales (vapor de sodio), que tienen una vida media corta y un mayor consumo energético, por luminarias LED (Diodo Emisor de Luz) que tienen una vida media más larga y son más eficientes. El análisis económico se basó en indicadores estándar de viabilidad de la inversión, como el valor actual neto (VPL), la recuperación de la inversión descontada y la tasa interna de rendimiento (TIR). finalmente, presenta análisis de datos con el fin de optimizar el sistema IP y reducir el consumo eléctrico en el municipio de Rosana.

Palabras clave: Alumbrado público; Eficiencia energetica; Diodo emisor de luz. 


\section{Introdução}

No Brasil, segundo o balanço energético, a massiva expressão continental possibilita uma diversidade para a matriz elétrica do país, sendo que cerca de $83 \%$ ocorrem de fontes renováveis e apenas 17\% de fontes não renováveis (ME, 2017). No tempo, novas formas de conversão de energia surgiram para que a demanda por energia elétrica pudesse ser suprida, porém mesmo com a diversidade das fontes de energia e empreendimento cada vez maiores no setor, ainda não é usualmente aplicado o uso dessa energia de forma eficiente, ainda mais quando observamos o cenário de infraestrutura e iluminação pública (IP) (Castro, 2021; Bernades et al, 2020; Carli et al, 2018) e seus riscos (Oliveira et al, 2021). Neste cenário, surgem questionamentos sob a ótica da Engenharia de Energia. O primeiro deles é: como a IP pode contribuir para melhorar a eficiência energética de uma cidade? E ainda, até que ponto é relevante a criação de um novo projeto de IP municipal que utilize a tecnologia Light Emitter Diode (LED)? Outro questionamento levantado é sobre a viabilidade financeira, ou seja, a quantidade existente de pontos de iluminação proporciona indicadores favoráveis para a realização do projeto?

Nesta linha, a pesquisa está direcionada para a renovação do sistema de IP do município de Rosana, Estado de São Paulo. Pretende-se, reduzir a potência instalada de energia através de dispositivos com uma melhor eficiência energética, minimizando o custo dessa energia. Consequentemente, esse estudo pode ser considerado ecologicamente correto, na utilização de lâmpadas e luminárias que sejam energeticamente eficientes e que não causem poluição luminosa.

O objetivo dessa pesquisa, consiste em analisar a redução da energia elétrica consumida pelo sistema de iluminação no município de Rosana sob a temática da IP e eficiência energética e propor um novo sistema de IP. Dessa forma, torna-se essencial mencionar quais são os componentes básicos de um sistema de IP a fim de uma explicação mais detalhada.

Importante desatacar que para se atingir os objetivos, é necessário alinhas os conceitos de IP e eficiência energética, além de aplicar os métodos para estimar o investimento financeiro, como Valor Presente Líquido (VPL), Payback descontado e Taxa Interna de Retorno (TIR). Dessa forma será possível analisar a viabilidade da implementação das mudanças propostas.

\section{Metodologia}

Para estudar os conceitos sobre IP e eficiência energética foi realizado um levantamento bibliográfico que consiste nos principais portais de periódicos acadêmicos sobre IP e eficiência energética (Campisi et al., 2018; da Fonseca, 2016; da Silva \& Lustosa, 2006). Essas leituras subsidiaram fichamentos que resultaram em análises de dados.

A fim de propor um novo sistema de IP que contemple o uso de luminárias com melhores indicadores de eficiência energética, foi feita uma análise quantitativa do Quadro de IP (QIP), disponibilizado pela distribuidora de energia Elektro Redes S/A por meio de arquivo do Software AutoCAD para contabilizar o sistema de IP atual. Também foi utilizado como base o Manual do Programa de Eficiência Energética ANEEL (2008), em que resultou na elaboração de tabelas contendo informações como a potência instalada $(\mathrm{kW})$, energia consumida (kWh/ano) e o custo anual da energia (R\$). Por fim, foi proposto um novo sistema que contempla o uso de luminárias mais eficientes e que atende às diretrizes sugeridas pela norma ABNT NBR 5101:2018 de procedimentos para IP.

Para estimar o investimento inicial foi realizada uma pesquisa de mercado por meio de envio de solicitações de orçamento para fornecedores especializados em IP (não serão divulgadas as propriedades intelectuais durante o andamento do trabalho para que não haja o foco na empresa e sim na viabilidade do projeto), tendo como objetivos obter um preço médio das luminárias e apresentar opções de empresas afirmando a acessibilidade da tecnologia. Por fim, foi realizado um estudo de viabilidade financeira a partir do investimento inicial, com o auxílio de alguns métodos de avaliação de investimentos, como Valor Presente Líquido (VPL), Payback descontado e Taxa Interna de Retorno (TIR), no qual resultou em uma estimativa de investimento para verificar a possibilidade de um novo sistema de IP. 


\section{Resultados e Discussão}

Em 1950 a cidade de Rosana foi fundada e participou da implantação dos planos de construção de um Ramal Ferroviário pela Companhia de Estrada de Ferro Sorocabana. O rio Paraná foi um grande aliado para o transporte por balsa e para a ferrovia, que deu continuidade no Estado do Mato Grosso do Sul até a cidade de Dourados - MS.

O município de Rosana fica localizado no interior do estado de São Paulo, na região do Pontal do Paranapanema, distante cerca de $750 \mathrm{~km}$ da capital. A cidade está inserida numa região de tríplice divisa entre os estados do Mato Grosso do Sul, Paraná e São Paulo tendo uma área territorial de aproximadamente $744 \mathrm{~km}^{2}$. Em seguida apresenta-se a Figura 1 que ilustra o mapa do município de Rosana.

Figura 1 - Mapa da Cidade de Rosana, Estado de São Paulo.

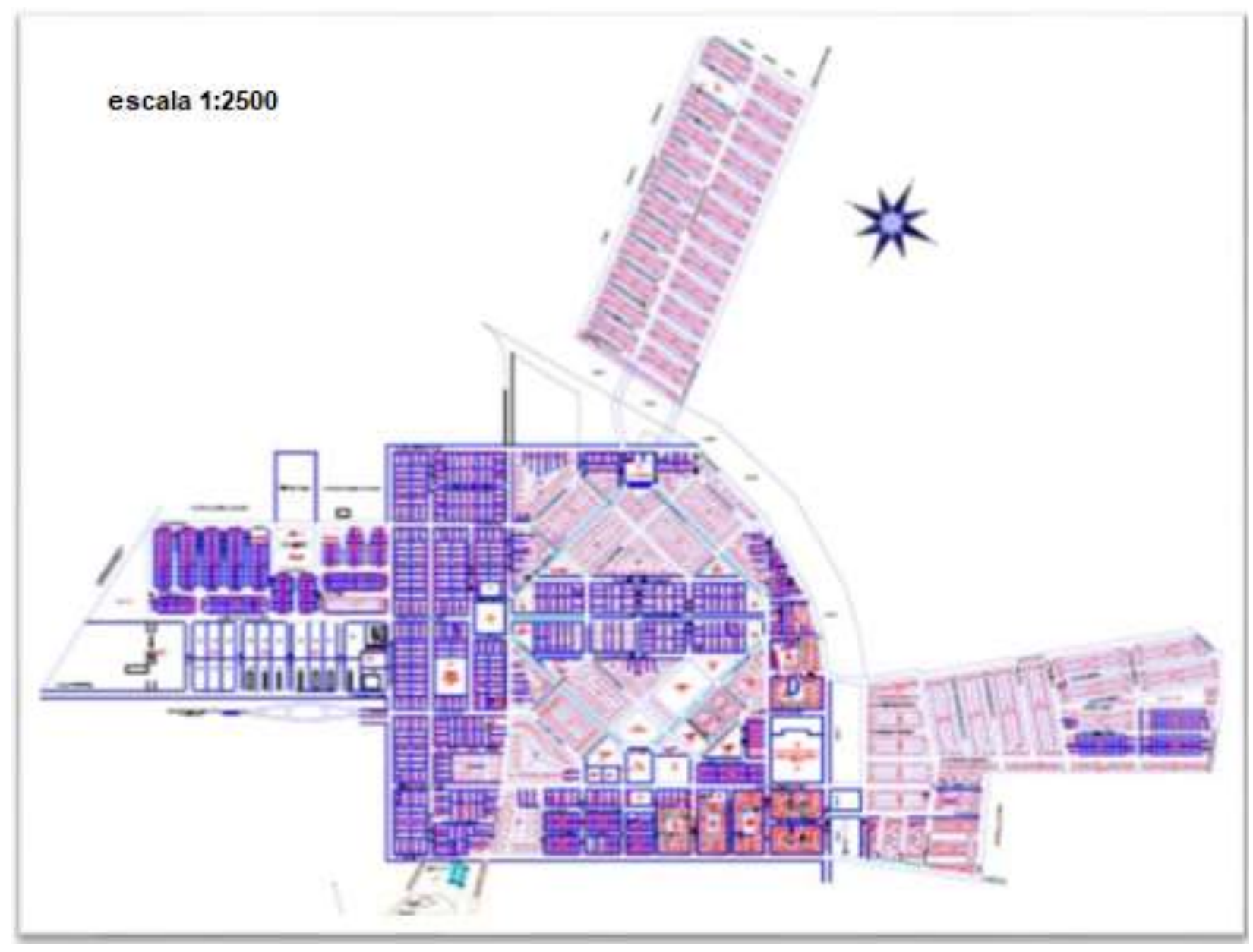

Fonte: Setor de Engenharia subprefeitura de Rosana (2020).

Um fato relevante para o desenvolvimento do município foi a construção da Usina Hidrelétrica (UHE) Porto Primavera, a empresa depois de realizar alguns estudos, decidiu construir uma cidade. Na década de 70, de modo que conseguisse alojar trabalhadores das duas grandes obras implantadas em seu tríplice fronteiro, a Companhia Energética de São Paulo (CESP) criou a 12 km da cidade de Rosana, o núcleo urbano de Porto Primavera, como ilustra a Figura 2. 
Figura 2 - Distrito de Primavera, Município de Rosana.

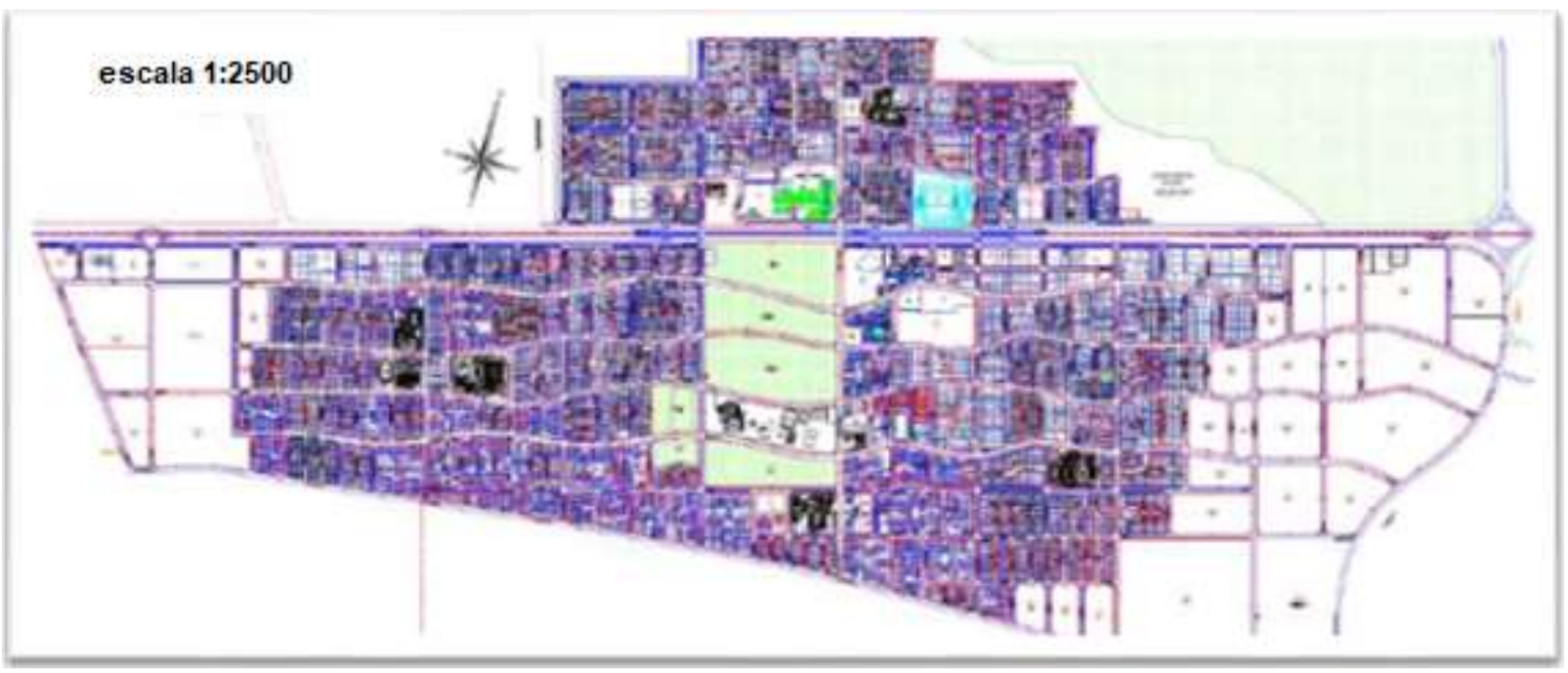

Fonte: Setor de Engenharia subprefeitura de Rosana (2020).

\subsection{Iluminação Pública Municipal}

O sistema de IP do município de Rosana é composto por lâmpadas de vapor de sódio de potências correspondentes à 70W, 100W e 250W distribuídos por Rosana, Primavera, Setor 1, 2, e 3 da Gleba e o bairro Beira Rio totalizando 3.612 pontos de iluminação. O Gráfico 1 mostra a quantidade de pontos existentes em cada localidade e a respectiva potência instalada.

Gráfico 1 - Distribuição dos pontos de IP e potência instalada por localidade do município.

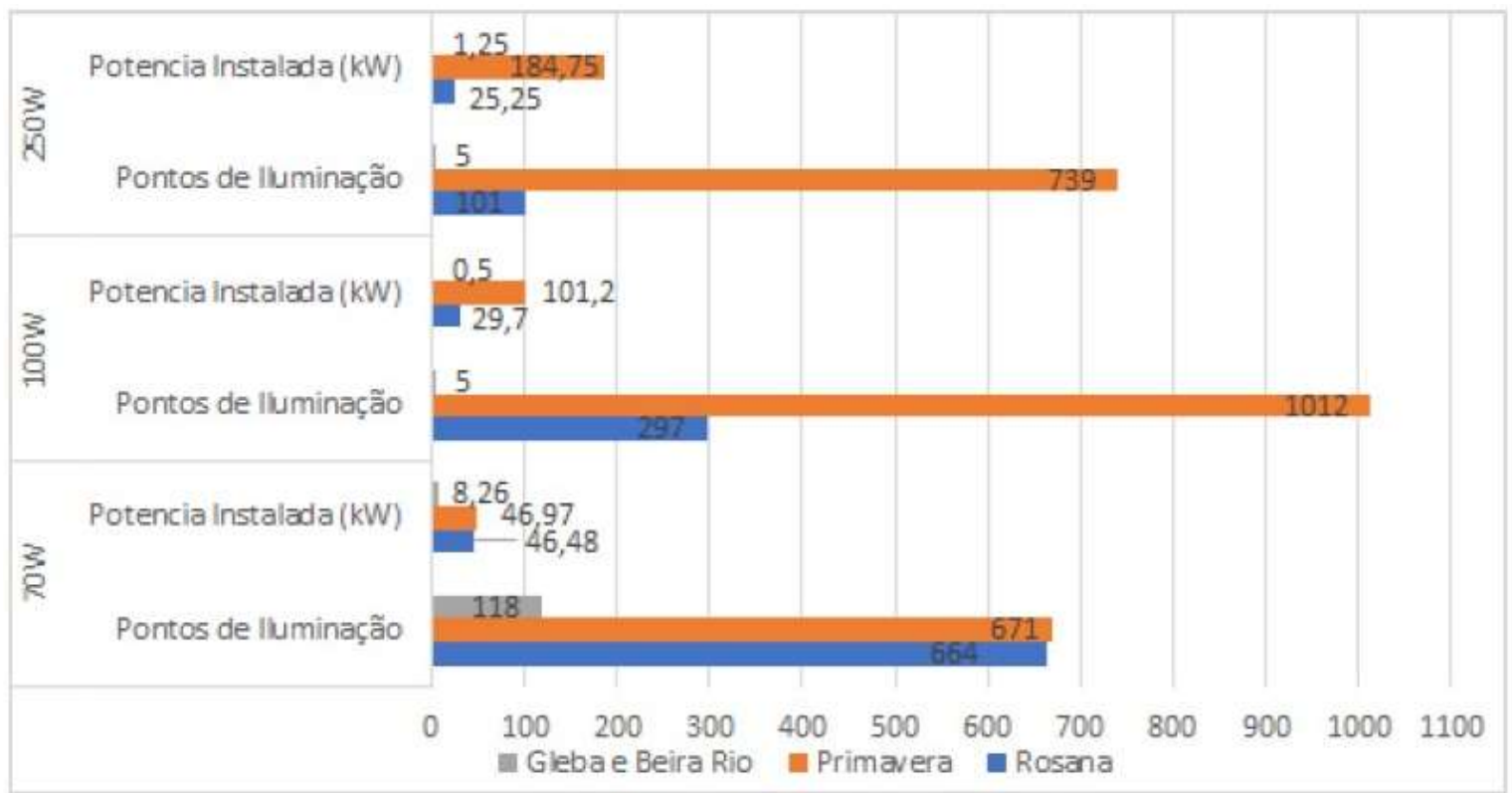

Fonte: Autores.

A partir do Gráfico 1 é notável que o distrito de Primavera é o líder em quantidade de pontos de iluminação ante todas as potências apresentadas, sendo o maior consumidor de IP, detendo 2/3 da potência instalada total do município. Em seguida, se tem a cidade de Rosana na qual possui menos da metade de pontos de iluminação do distrito de Primavera e pouco menos de $1 / 3$ da potência instalada total.

Por fim, se tem os setores 1,2 e 3 da Gleba e o bairro Beira Rio, sendo ao todo 128 pontos de IP, esse baixo número 
comparado às outras localidades se deve pelo fato de serem bairros rurais com pouca infraestrutura e uma quantidade menor de moradores.

Nesse sentido, o projeto de eficiência energética deste trabalho foi elaborado com base no Manual de Elaboração do Programa de Eficiência Energética, da Agência Nacional de Energia Elétrica (ANEEL), aprovado pela Resolução Normativa n o 300, de 12 de fevereiro de 2008, em conformidade com o item 5.1 "Sistema de Iluminação", de forma a considerar o sistema atual existente na cidade (Vapor de Sódio), o sistema proposto com luminárias LEDs e os resultados esperados.

No Gráfico 2 é apresentada uma comparação entre os dois sistemas de IP, a potência instalada, a energia consumida e a quantidade total de luminárias pelos dois sistemas.

Gráfico 2 - Comparação entre os sistemas de iluminação.

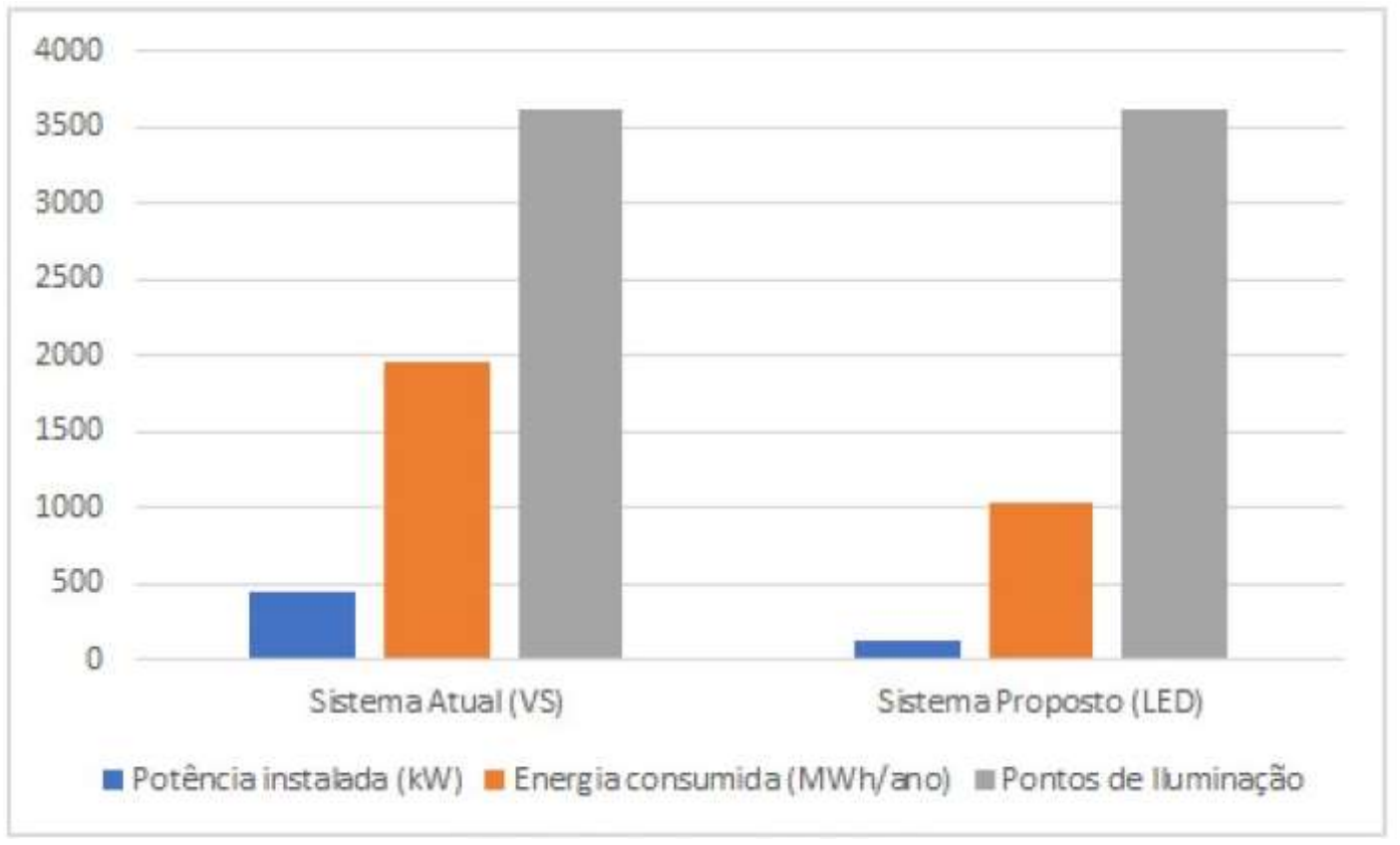

Fonte: Autores.

É possível visualizar uma redução de aproximadamente $50 \%$ da potência instalada e consequentemente da energia consumida. Assim, é perceptível que a quantidade de pontos de IP não se altera em nenhum dos sistemas.

A partir do exposto acima pode-se mencionar a Gráfico 3, da qual trata do benefício financeiro obtido apenas pela redução da energia consumida do atual sistema de iluminação de lâmpadas a vapor de sódio, pelo sistema proposto por luminárias LED. 
Gráfico 3 - Comparação entre os sistemas de iluminação atual e o proposto.

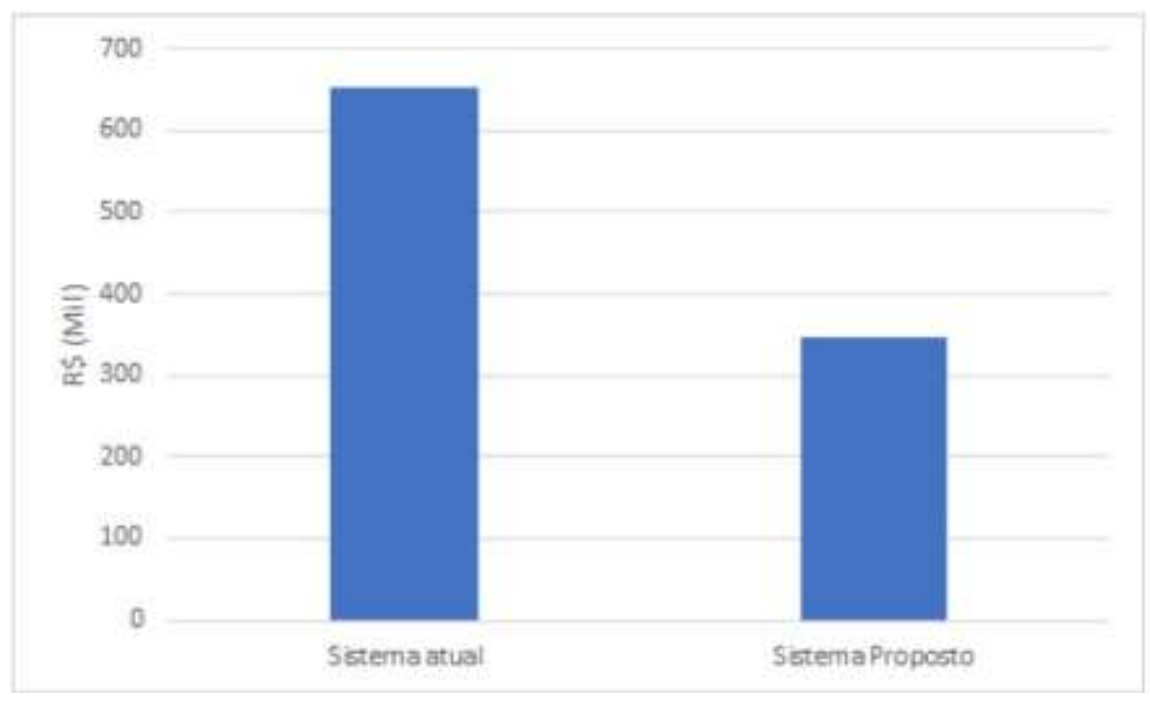

Fonte: Autores.

Tal redução é notável por ser equivalente a aproximadamente metade do custo atual com IP. Para elaboração dos dados apresentados nas Figuras 2, 3 e 4 utilizou-se as Equações 1, 2 e 3:

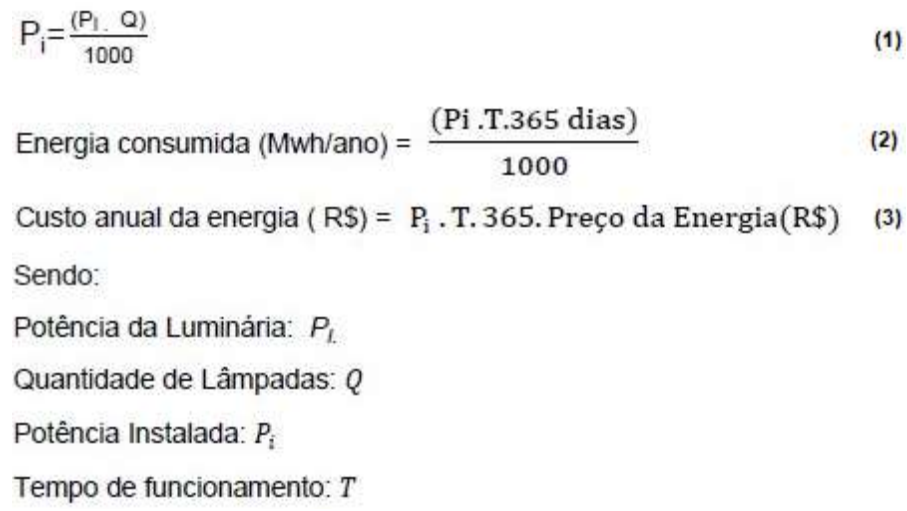$$
P_{i}=\frac{\left(P_{1}, Q\right)}{1000}
$$

Onde:

- Tempo de funcionamento(h) é definido como 12h de acordo com manual de eficiência energética da ANEEL 2008;

- Preço da Energia (R\$) é definido pela distribuidora Elektro e a tabela de tarifação de baixa tensão, sendo de R\$/kWh 0,33303 a tarifação do subgrupo B4b-bulbo da Lâmpada para baixas tensões;

Assim o Gráfico 4 traz os resultados esperados com a troca das lâmpadas de Vapor de Sódio por luminárias LED equivalentes.

Gráfico 4 - Resultados Esperados.

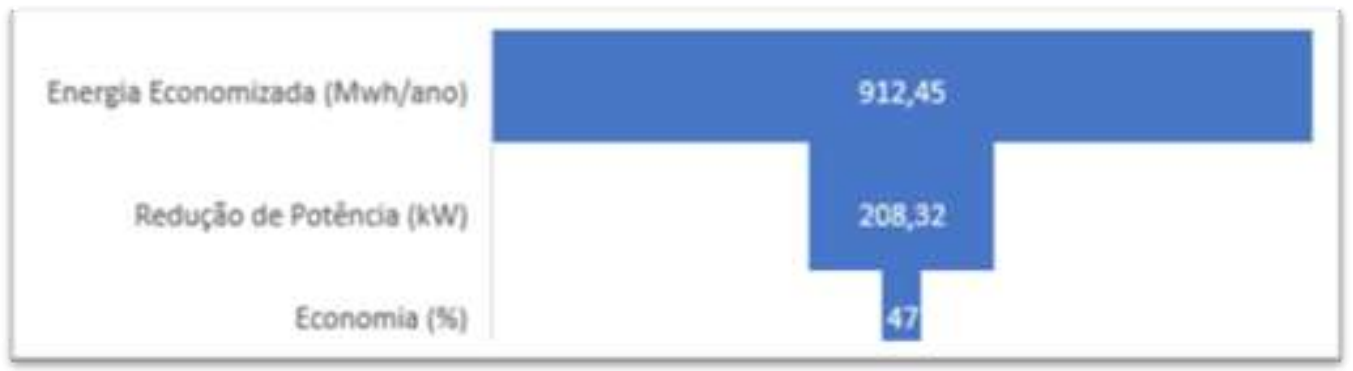

Fonte: Autores. 
Pode-se observar números promissores em relação à eficiência energética proposta com o sistema de iluminação LED, no qual reduz 912,45 Mwh/ano de energia e uma redução de potência de 208,32 kW, isso corresponde a uma economia de $47 \%$.

\subsection{Análise Econômica}

O estudo de viabilidade financeira do projeto é feito a partir da avaliação do custo das luminárias LED por fornecedor, o ônus da mão de obra. Tendo esse investimento contabilizado, utilizou-se de indicadores financeiros propostos neste trabalho para uma avaliação coesa ao longo do tempo.

\subsection{Custo da Aquisição das Luminárias e Mão de Obra}

Para a realização de um estudo de caso mais robusto e concreto fez-se uma pesquisa com 4 fornecedores de luminárias LED que possuem o selo PROCEL, garantindo a legitimidade das especificações técnicas e eficiência dos equipamentos.

Para definição dos custos com a aquisição de luminárias é apresentado o quadro abaixo que traz o orçamento inicial de cada fornecedor.

Quadro 1 - Orçamentos obtidos no mercado.

\begin{tabular}{|c|c|c|c|}
\hline \multicolumn{4}{|c|}{ Fornecedor III } \\
\hline Potência da luminária & Preço & Qtd & Total \\
\hline Luminária $30 \mathrm{~W}$ & 266,94 & 1453 & $389,863,82$ \\
\hline Luminária $60 \mathrm{~W}$ & 373,43 & 1314 & $490.687,02$ \\
\hline \multirow[t]{2}{*}{ Luminária 150W } & 769,50 & 845 & $650.227,50$ \\
\hline & & Total & $1.528 .778,34$ \\
\hline \multicolumn{4}{|c|}{ Fornecedor IV } \\
\hline Potência da luminária & Preço & Qtd & Total \\
\hline Luminária $30 \mathrm{~W}$ & 373,23 & 1453 & $542.303,19$ \\
\hline Luminária $60 \mathrm{~W}$ & 419,12 & 1314 & $550.723,68$ \\
\hline \multirow[t]{2}{*}{ Luminária $150 \mathrm{~W}$} & 524,16 & 845 & $442.915,20$ \\
\hline & & Total & $1.535 .942,07$ \\
\hline
\end{tabular}

Fonte: Autores.

Para determinar o custo geral com a mão de obra foi contabilizado o valor em Reais (R\$) por hora (h) de serviço prestado de um eletricista profissional e mais um ajudante (auxiliar) da área. Os valores base para o cálculo foram encontrados no Boletim Referencial de Custos - Tabela de Serviços, da Companhia Paulista de Obras e Serviços (CPOS), Versão 175.

Supondo que o serviço de troca de luminárias demore 30 minutos e a intenção é trocar 3.612 pontos, assim ambos profissionais levariam ao todo 1806 horas para a realização completa do serviço. Com isso constrói-se o Quadro 2 a seguir. 
Quadro 2 - Custo Mão de Obra.

\begin{tabular}{|l|c|c|c|}
\hline & Valor(RS)/Serviço(h) & Total de horas trabalhadas(h) & Total (R\$) \\
\hline Eletricista & 9,55 & 1806 & $17.247,30$ \\
\hline Ajudante & 6,55 & 1806 & $11.829,30$ \\
\hline \multicolumn{2}{|c|}{ Total } & $29.076,60$ \\
\hline
\end{tabular}

Fonte: Autores.

\subsection{Viabilidade Financeira}

Foi necessária a adequação das potências das luminárias no cálculo da eficiência energética, devido ao mercado não conter exatamente as potências teóricas escolhidas pelo autor e esse fato ter direta relação com a viabilidade financeira do estudo aqui exposto.

Foram mensurados quatro indicadores de viabilidade de projetos comumente utilizados na área de gerência de projetos, sendo eles: Taxa mínima de atratividade (TMA), Taxa interna de retorno (TIR), Valor presente líquido (VPL) e Payback composto.

Para o cálculo da TMA foram levados em conta 3 fatores, a taxa de juros Selic utilizada como base de cálculo para títulos do governo ou mesmo para títulos de renda fixa estabelecida em 4,25\% ao ano, pelo Comitê de Política Monetária (COPOM) em 16 de junho de 2021. O risco do investimento estipulado em 1\% pelo autor por se tratar de um projeto simples e a liquidez do projeto que também foi avaliada em 1\% para base de cálculo. Dessa forma, a taxa mínima de atratividade é admitida em 6,25\% ao ano.

A TIR é calculada pelo próprio programa, correlacionando o investimento inicial e os descontos proporcionados pela eficiência energética que são convertidos no fluxo de caixa do projeto ao longo da vida útil do equipamento, sendo que nenhuma outra taxa seja contabilizada.

O VPL também é calculado por meio de uma planilha eletrônica, porém com uma fórmula que relaciona a TMA com o valor monetário obtido pela eficiência energética do projeto, de modo que a intenção do indicador é estimar os ganhos futuros com o impacto da descapitalização ao longo dos anos.

Já o Payback composto é calculado por uma divisão onde o numerador é a subtração entre o ano que o investimento foi pago e valor presente acumulado do mesmo ano, já o denominador é o valor presente líquido do ano posterior. Assim foi possível obter o Quadro 3 que trata dos indicadores financeiros obtidos para cada fornecedor levando em consideração o orçamento inicial juntamente com o custo da mão de obra estipulada.

Quadro 3 - Indicadores de viabilidade financeira obtidos de cada fornecedor.

\begin{tabular}{|c|c|c|c|c|}
\hline Fornecedores & Vida ütil(anos) & VPL Acumulado(R\$) & TIR(\%) & Payback(anos) \\
\hline I & 23 & $1.538 .132,82$ & 13 & 9,4 \\
\hline II & 23 & $1.510 .050,76$ & 13 & 8,7 \\
\hline III & 11 & $783.649,57$ & 15 & 6,9 \\
\hline IV & 11 & $834.624,45$ & 15 & 6,6 \\
\hline
\end{tabular}

Fonte: Autores.

Através do Quadro 3 é possível obter o VPL acumulado ao longo da vida útil de cada equipamento fornecido. Além disso, a Taxa Interna de Retorno sobre o investimento de todos os fornecedores é maior que a Taxa Mínima de Atratividade e 
maior que a Taxa de Juros Selic atual. Outra análise aferida é o Payback para as luminárias LED de vida útil igual a 23 anos que se dá antes da metade de sua vida útil, diferentemente das luminárias de 11 anos que o Payback se dá após a metade de sua vida útil. Dessa forma, foi possível fazer a projeção dos saldos financeiros, relacionado com os indicadores VPL e Payback a longo da vida útil dos equipamentos apresentados por cada fornecedor.

\section{Conclusão}

Tendo como base a arrecadação do município de Rosana no ano de 2020, a implementação do projeto corresponde de $1,7 \%$ a $2,5 \%$ do total arrecadado. Entende-se que o custo total para implementação do projeto foi variável devido ao levantamento feito com quatro fornecedores, sendo que dois fornecedores apresentam um equipamento com vida útil de 102.000h e o custo total contabilizando o serviço de mão de obra foi de $R \$ 2.154 .755$ e $R \$ 2.215 .882$, respectivamente. Já em relação aos fornecedores III e IV a vida útil do equipamento apresentado é de 50.000h com um orçamento total de $\mathrm{R} \$ 1.586 .931$ e $\mathrm{R} \$ 1.535 .956$.

No âmbito da eficiência energética municipal, os resultados afirmam que haverá uma redução de $47 \%$ da potência instalada que gera uma economia anual em energia de 912,45 MWh. Contudo, é significativo lembrar que o sistema atual consome 1.946,3 MWh/ano e essa redução traz uma economia monetária anual de $\mathrm{R} \$ 305.941,67$ para os cofres do município.

Outro fato importante a ser mencionado está relacionado aos indicadores de viabilidade financeira que se mostraram promissores pelo fato do Valor Presente Líquido de todos os fornecedores serem positivos, a TIR estar na média de $14 \%$ e o Payback próximo a meia vida das luminárias. Assim, sendo possível reafirmar a implementação do novo projeto de IP.

Dessa forma, fica evidente que o projeto possui conceitos razoáveis de originalidade devido à falta de projetos na região onde está localizado o município de Rosana, também pode ser visto a aplicabilidade do mesmo pelo custo relativamente baixo mediante a arrecadação anual do município, assim a relevância que se dá no âmbito econômico, energético e social.

Como trabalho futuro, se deseja analisar os impactos financeiros e econômicos em projetos de Redes Elétricas Inteligentes, implementando sistema inteligentes como sensores e Internet das Coisas (IoT) nos sistemas de iluminação do município de Rosana.

\section{Referências}

Bernades, D. M., Celeste, W. C., \& Chaves, G. D. L. D. (2020). Eficiência energética na iluminação pública urbana: revisão bibliográfica dos equipamentos e tecnologias. Research, Society and Development, 9(7).

Carli, R., Dotoli, M., \& Pellegrino, R. (2018). A decision-making tool for energy efficiency optimization of street lighting. Computers \& Operations Research, 96, 223-235.

Castro, N. J. (2021). Eficiência Energética Na Iluminação Pública e o Plano Nacional De Eficiência Energética.

Campisi, D., Gitto, S., \& Morea, D. (2018). Economic feasibility of energy efficiency improvements in street lighting systems in Rome. Journal of Cleaner Production, 175, 190-198.

da Fonseca, D. C. F. (2016). Eficiência Energética Da Iluminação Pública Automatizada: Estudo De Caso Na Cidade De Caruaru. Estudo de Caso na Cidade de Caruaru. 06/10/2016. http://www.abepro.org.br/biblioteca/tn_sto_234_364_29766.pdf.

da Silva, L. L. F., \& Lustosa, L. (2006). Iluminação Pública no Brasil: Aspectos energéticos e institucionais. Universidade Federal do Rio de Janeiro.

Djuretic, A., \& Kostic, M. (2018). Actual energy savings when replacing high-pressure sodium with LED luminaires in street lighting. Energy, $157,367-378$. dos Santos, E. R. (2005). A Iluminação Pública Como Elemento de Composição da Paisagem Urbana.

CGEET (2021). Companhia de Geração Térmica de Energia Elétrica. Histórico. http://www.eletrosul.gov.br/a-empresa/quem-somos/historico/cgtee. Guimarães (2018). Livro Física 3 Anos - Eletromagnetismo. Física Moderna. 16/09/2018. https://issuu.Com/yasmina.A.A.N/docs/fisica-v3-guimar_espiqueira-carron.

Lima, L. C. (2019). Iluminação Pública História, Tecnologias E Aplicações. Tese de Doutorado. Universidade Federal do Rio de Janeiro - UFRJ.

Lopes, L. B. (2014). Uma Avaliação da Tecnologia Led na Iluminação Pública. Universidade Federal do Rio de Janeiro - UFRJ. 
Research, Society and Development, v. 10, n. 17, e246101725044, 2021

(CC BY 4.0) | ISSN 2525-3409 | DOI: http://dx.doi.org/10.33448/rsd-v10i17.25044

Mascaro, L. E. A. R. D. (2006). A iluminação do espaço urbano. Arqtexto. n. 8, p. 20-27.

MME. Ministério de Minas e Energia (2007). Plano Nacional De Energia 2030. Brasília, 2007.

MME. Ministério de Minas e Energia (2011). Plano Nacional De Eficiência Energética. Brasília.

Nonino, R., \& Tanaka, S. (2018). Desenvolvimento de um aplicativo para melhorar a administração da iluminação pública visando cidades inteligentes. Revista Terra \& Cultura: Cadernos de Ensino e Pesquisa, 34(esp.), 29-38.

Nunes, D. J. B. (2019). Eficiência energética e manutenção preventiva na gestão de iluminação pública (Doctoral dissertation, Instituto Politécnico do Porto. Escola Superior de Tecnologia e Gestão).

Oliveira, K. R. de, Silva, J. F. R. da, \& Violin, F. L. (2021). Análise quantitativa da intensidade de riscos em projetos de smart grid no setor privado brasileiro. Research, Society and Development, 10(17), e243101724947. https://doi.org/10.33448/rsd-v10i17.24947.

Procel (2017).Eletrobras. Http://www.procelinfo.com.br/resultadosprocel2017/Docs/Rel_procel2017_web.pdf. São Paulo.

ME (2017). Ministério da Economia. (Org.). Programa Brasileiro de Etiquetagem. https://www.gov.br/inmetro/pt-br/acesso-a-informacao/perguntasfrequentes/avaliacao-da-conformidade/programa-brasileiro-de-etiquetagem-pbe/qual-o-objetivo-do-programa-brasileiro-de-etiquetagem-pbe.

Silveira, R. M. C. F. (2009). Ciência, Tecnologia e suas Relações Sociais: A Percepção de Geradores de Tecnologia e Suas Implicações na Educação Tecnológica. 15/03/2009. https://www.scielo.br.

Thalheimer, L. T. F., \& Taube, J. (2021). Análise das Condições Lumínicas do Sistema de Iluminação Pública de Led no Município de São Miguel do Oestesc. Seminário de Iniciação Científica e Seminário Integrado de Ensino, Pesquisa e Extensão.

Thiel, G. G., Ensslin, S. R., \& Ensslin, L. (2017). Street lighting management and performance evaluation: opportunities and challenges. Lex Localis, 15(2), 303. 